\title{
A MULHER OPERÁRIA EM JOINVILLE: Situação, Preconceito e Discriminação. (Projeto de Pesquisa).
}

\author{
AFONSO IMHOF \\ da Faculdade de Filosofia, Ciências e Letras de \\ Joinville (SC).
}

\section{JUSTIFICATIVA.}

O IBGE em sua categorização de Pessoas Economicamente Ativas dá um percentual de $20 \%$ de participação feminina num contingente de 30 milhões de trabalhadores. "A participação da mulher tem aumentado consideravelmente de ano para ano, à taxa média de 1\%" (REZENDE, 1976).

Com base em REZENDE (1976), podemos avaliar estatisticamente a menor percentagem da participação feminina no trabalho. Entre 1970 e 1972 o contigente de mulheres empregadas cresceu $8 \%$ na região da Guanabara e Rio de Janeiro. No mesmo período, o crescimento da mão-de-obra feminina em São Paulo foi de $19,52 \%$. Nas regiões da Guanabara, Estado do Rio e São Paulo, onde se concentram os maiores polos industriais do Brasil e que representan $31,60 \%$ da força de trabalho do país, o número de mulheres empregadas em 1973 alcançou 2.906.160 contra 7.450 .588 homens. São Paulo, que detém o maior índice de mão-de-obra ocupada no país, possuía em 1973 o número de 1.991 .253 mulheres empregadas. MARTINS (1972), estribado no relatório Mão-de-Obra Feminina, do Grupo de Planejamento Setorial da Secretaria do Trabalho e Administração do Governo de São Paulo, dá o percentual de $28 \%$ para São Paulo e menos de $10 \%$ para o Brasil.

$\mathrm{O}$ aumento da participação de mão-de-obra feminina em quase todo o mundo, apesar da situação percentual ser sempre inferior à masculina, teve, como explicam GILBERT e ISAMBERT-JAMATTI (1973: 319), 
"uma das razões essenciais do recurso maciço às mulheres nos diferentes empregos e em especial na indústria, foi a possibi. lidade de persuadi-las a aceitarem salários mais baixos". explica:

SAFFIOTTI (1969: 260), por sua vez, em níveis brasileiros,

"A concepção do trabalho feminino como um trabalho subsidiário favorece a oferta e aceitação de salários mais baixos que os masculinos".

Verificou-se, no Município de Joinville, no período compreendido entre 1960 a 1976 , um grande crescimento industrial, aumentando consideravelmente o nível de empregos na zona urbana e um aumento no montante de força de trabalho feminino efetivo.

Experimentou este Município reflexos do crescimento industrial ocorrido no Governo Juscelino, mais especificamente o reflexo da indústria automobilística. Esta indústria, necessitando de metalurgias e fundições de alto nível de qualidade técnica, encontrou numa das empresas locais (fundição) a fornecedora de uma boa porção de auto-peças.

Paralelamente ao crescente desenvolvimento dessa empresa, hoje a maior do Estado, outras emergiam e se expandiam rapidamente - a de plástico e refrigeradores, juntando-se a outras grandes mais antigas, como por exemplo, as têxteis, malharias, confecções e a química.

Em consequiência, Joinville passou a atrair mão-de-obra originária das zonas rurais da micro-região que polariza e de outras cidades carentes muitas vezes de oferta de trabalho.

Joinville vem observando taxas de crescimento demográficas excepcionais bastando caracterizar que o Município cresceu no período $1960 / 70$ à taxa de $6 \%$ a.a. e a cidade aproximadamente a 7,3\% a.a., possuindo cerca de $90 \%$ da população na zona urbana.

A economia da Região polarizada por Joinville (micro-região) (1) manteve acelerado ritmo de crescimento industrial de 7,3\% a.a. no período $60 / 68$, sendo que entre 65 a 68 alcançou um ritmo excepcional de $11,5 \%$ a.a., detendo o maior volume da produção industrial do Estado de Santa Catarina.

(1). - A micro-região é composta dos seguintes municípios: Joinville, Araguarí, São Francisco, Barra Velha, Garuva, Guaramirim, Jaraguá do Sul, Schroeder, Corupá, Campo Alegre, São Bento do Sul e Rio Negrinho. 
Como se depreende, ocorre um crescimento industrial paralelo ao de Joinville na micro-região, concorrendo para diminuir a disponibilidade da mão-de-obra em Joinville proveniente da zona rural de Municípios vizinhos.

Não havendo no Município um exército de reserva masculino (2), as indústrias estão recrutando desde 1975 mão-de-obra masculina em Municípios mais próximos, realizando, inclusive, campanhas aliciatórias e, a título de atraí-la, oferecem transportes coletivos diários do lar ao trabalho e do trabalho ao lar.

A mulher em Joinville era até 1974 mão-de-obra destinada principalmente para as indústrias têxteis (tecelagem, fiações, malharias, confecções), plásticas, de refrigeradores e química. Era-lhe recusada a entrada na indústria metal-mecânica, mas a partir desse ano de 1974 assistimos à entrada da mulher como operária em uma empresa (a maior do Município) e recentemente em outra menor.

"Há dois anos atrás, a Fundição Tupy fêz a primeira experiência com um grupo de cinqüenta mulheres. A empresa fez um amplo estudo e chegou à conclusão de que havia muitos preconceitos, principalmente por ser este um tipo de experiência pioneira, e porque a maioria da população não tinha ainda uma mentalidade aberta para uma situação" (3) .

\section{A mesma matéria deste Jornal diz que a}

"experiência com as primeiras 50 mulheres demonstrou resultados altamente positivos, modificando, inclusive, os padrões de rendimento estabelecidos pela empresa, com base no trabalho masculino" (...).

Acreditamos que essa mudança dos compradores de força de trabalho, não tem como causa única a falta de mão-de-obra masculina em Joinville ou até mesmo na micro-região aludida. Uma outra causa indutora do emprego, possivelmente seja a manutenção dos atuais níveis salariais. A falta de um exército de reserva masculino é evidente, e, com relação à disponibilidade de mão-de-obra feminina acreditamos existir, entretanto, os envolvimentos domésticos, principalmente o cuidado dos filhos, impedem a concretização como exército de reserva e sua caracterização como tal.

(2). 一 HARNECKER (Marta), (1973:251-2): Exército de Reserva trabalhadores disponiveis, desempregados ou excedentes.

BERLINCK (1975.117) utiliza o termo exército industrial de reserva.

(3). - Mão-de-obra feminina resolve problema de empresa do Norte. Jornal "O Estado", Florianópolis, 06 de maio, 1976, p. 9. 
Está comprovado pela PLANISUL (1975) que no período 1960/ 70 o emprego industrial em Joinville cresceu a $8 \%$ enquanto a população urbana cresceu $7,3 \%$ e no Município, a $6 \%$. Como se pode deduzir, há um índice menor de crescimento populacional em relação às reais necessidades do crescimento de empregos.

Poderíamos admitir que a mulher também tem oportunidade de vender sua força de trabalho em face da presente falta de um exército de reserva masculino.

Ocorrem-nos, entretanto, outras hipóteses que desejamos investigar, e utilizar um referencial teórico para explicar a realidade.

\section{DEFINIÇĀO DA PROBLEMÁTICA E HIPOTESE DE TRABALHO.}

O persistente empobrecimento das camadas de renda mais baixa da população urbana constitui um fenômeno estruturado da acumulação capitalista .

Observamos que a atual defasagem salarial do operário leva a mulher a vender sua força de trabalho nas indústrias, a fim de aumentar o índice salarial da família.

A nossa primeira hipótese de trabalho nasce relacionada a esse empobrecimento. Desejamos investigar a relação do empobrecimento, fruto da defasagem salarial e a entrada da mulher casada no mercado de trabalho.

Observamos famílias migrantes do meio rural da micro-região para o meio urbano local, formadas por casais de uma faixa etária em torno dos 40-50 anos, verem-se obrigados a colocar a mulher à disposição do mercado de trabalho, ocorrendo uma nova adaptação da população nesse novo meio.

Essas famílias geralmente não concebiam em seu meio rural o trabalho assalariado da mulher casada como necessário, porquanto cabia ao homem casado assalariar-se e manter o lar. À mulher solteira, mesmo da zona rural, é facultado e aprovado vender sua força de trabalho na zona urbana, quer como "doméstica" ou operária, etc.

E possível haver uma desaprovação generalizada no meio rural para o assalariamento da mulher casada. Há uma concepção preconceituosa generalizada na sociedade, que vê a saída do lar para assala- 
riar-se como um caminho para a prostituição ou para o prejuízo da educação dos filhos, etc. Migrando para Joinville, ocorre uma mudança na concepção desaprovatória: o homem permite a saída dela do lar e enfrenta essas barreiras psicológicas e morais.

Parece-nos que esse homem é condicionado a permitir e incentivar o trabalho assalariado de sua mulher em face de sua defasagem salarial (arrocho salarial).

Nossa hipótese torna-se consistente quando verificamos que essa mudança, que se opera nas famílias proletárias recém-imigradas, também passa a ser constante em antigas famílias provenientes de zonas rurais, compelindo a mulher a entrar no mercado de trabalho por força do empobrecimento progressivo.

Por outro lado, a progressiva entrada da mulher no mercado de trabalho tido anteriormente a 1974 como masculino não poderá ser explicada à contento com a perspectiva do empobrecimento das camadas de renda mais baixa da população urbana. O condicionamento da intensa atividade propagantística do comércio dirigida à classe operária pode ser também um fator importante.

Nossa hipótese sobre esse novo comportamento de oferta de empregos, ocorrido após esse ano, está em grande parte na manipulação dos mecanismos institucionais gerais e setoriais que possibilitam a espoliação em maior grau do trabalho feminino. Ainda nessa ordem de hipóteses, achamos que a manipulação de um contingente feminino assalariado não se restringe unicamente a pagar menos (discriminação cuja existência tentaremos empiricamente comprovar), mas é efetuada também na exploração das potencialidades femininas advindas dos papéis a ela reservados pela nossa sociedade (submissão, responsabilidade, místicas de mãe, disciplina, etc.) .

A empresa pioneira na adoção do emprego de mulheres casadas e de solteiras em 1974 revela-se otimista quanto aos aspectos de produção, disciplina e assiduidade. São esses aspectos, além da discriminação salarial que possivelmente pode estar ocorrendo, que nos levam à formulação da hipótese sobre a manipulação econômica da oferta de trabalho à mulher.

Em termos de manipulação, podemos ainda caracterizar hipoteti-camente uma supervalorização da mulher relacionada à produtividade, podendo ocorrer futuramente uma discriminação em relação ao homem no mercado de trabalho.

O homem poderá sofrer essa discriminação na seleção. Essa mudança poderá forjar-se em nossso meio para garantir ao empresário 
um maior acúmulo de capital gerado pela mais-valia. Ela é encarada presentemente pelos empregadores locais da mesma forma como apresentou BOSI (1972: 86-7):

"A mulher é na indústria aquele operário designado como sem qualificação, o que executa operações simples e repetidas que exigem apenas atenção e coordenação motora. Seu treinamento pede destreza em poucas operações e explicações tecnológicas elementares (...) e que as pesquisas nos mostram mais preocupado com o salário que com a natureza do seu trabalho".

Institucionalmente desconhecemos as vantagens proporcionadas à mulher, e à indústria, pela Lei Federal no 6.136, de 07-11-74, e regulamentada pelo Decreto $\mathrm{n}^{\mathrm{0}}$ 75.207, de 10-01-75, que tratam do salário-maternidade, bem como da revogação da proibição de trabalhos noturnos às mulheres após às 22 horas.

Cumpre-nos investigar se também nessa empresa e noutras a oferta de empregos femininos cresceu com base nas vantagens que a respectiva Lei veio trazer ao empregador, ou sejam, a transferência do salário maternidade para o INPS. Anteriormente a essa Lei, a Justiça do Trabalho vinha reunindo um grande número de ações ajuizadas contra empregadores que utilizavam o expediente das demissões à mulher gestante ou àquela que concebera.

A manipulação dos mecanismos institucionais, gerais e setoriais referidos acima são demonstrados por BERLINCK (1975) . O empobrecimento é consequiência de um mecanismo espoliatório - o arrocho salarial. O Fundo de Garantia por Tempo de Serviço FGTS, em nósso meio operário ocasiona uma rotatividade da mão-de-obra, objetivando proporcionar menores reajustes salariais. Indústrias têxteis, tradicionalmente compostas de proletariado feminino, em períodos críticos, despedem em massa e reempregam em massa após três meses. Fato análogo decorre em outras indústrias onde o maior contingente proletário é masculino. A rotatividade se processa assim: indústria $\mathrm{A}$ despede $\mathrm{X}$ operários, indústria $\mathrm{B}$ despede $\mathrm{Y}$; a firma $\mathrm{B}$ emprega os despedidos de $\mathrm{A}$ e vice-versa. Os despedidos são geralmente os mais antigos que percebem uma remuneração superior aos novos. Admitindo-s novos operários, eles vão proporcionar uma maior acumulação capitalista, porquanto são mantidos baixos níveis salariais .

A problemática aqui apresentada leva a admitirmos a proposição de CARVALHO (1972: 47) de que o

"trabalho feminino no Brasil é encarado como subsidiário e, como tal, recebe salários subsidiários". 
Esta é uma concepção da sociedade industrial e do patronato. Em períodos críticos da indústria têxtil, registra-se a dispensa em massa da mulher, porquanto esta concepção vê a mão-de-obra feminina como subsidiário e temporária e a do homem, permanente e efetiva.

Despedir o homem operário (que é minoria nessa indústria) ao invés da mulher, fere o machismo, o orgulho do chefe de família, 0 mantenedor do lar. Supomos haver um consenso que legitima essa concepção machista.

Concebendo-se assim o trabalho subsidiário e a colocação da mulher nas flutuações da oferta, sedimenta a manipulação patronal de um contigente feminino no fluxo demissão-readmissão.

Este preconceito machista, aliado à sua falta de consciência de classe, facilita, certamente, essa manipulação patronal.

\section{METODOLOGIA.}

Além da revisão bibliográfica pertinente à problemática em apreço, estudaremos a legislação trabalhista e sindical. Empreenderemos um estudo histórico-estatístico e comparativo da classe operária, desde o início do Governo Juscelino até 1964, e, depois desse ano, até os dias atuais.

Através de estudos históricos desejamos verificar os períodos em que ocorreram lutas de classes, lideradas ou não por sindicatos; também comparar o poder aquisitivo da classe operária nos períodos compreendidos entre 1956/1964 e 1964/1976.

Nesse último período reside, talvez, a origem do agravamento da pauperização do operário brasileiro, que, em termos locais, desejamos detectar, como uma contingência à saída da mulher do lar para o assalariamento na indústria.

A política salarial implantada após esse último período ficou conhecido como "arrocho-salarial" e as consequiências desse mecanismo institucional deverão ser por nós meticulosamente analisadas e interpretadas à luz da hipótese do empobrecimento do operário .

A nível local, utilizaremos a técnica da entrevista individual, padronizada através de um formulário para possibilitar a quantificação estatística e, assim, deduzir dados relacionados à problemática. 
Necessariamente, os formulários estarão compostos com a necessidade de se saber - o Município de origem, causas da migração, procedência urbana ou rural, época da migração, empregos anteriores, salários, idade, número de filhos, necessidade que, compeliram a mulher a trabalhar, proprietários ou não de imóvel em Joinville, admissões, readmissões, o papel da mulher, a concepção da mulher como assalariada, a opção quanto ao FGTS ou ao sistema de estabilidade, etc.

Nas indústrias têxteis pesquisaremos, através de entrevistas subjetivas não padronizadas, os funcionários qualificados para dimensionar a política salarial e empregatícia. Pretendemos levantar as preferências de oferta de emprego feminino quanto ao estado civil (casada ou solteira) anteriores ao surgimento da Lei 6.136, que incumbiu o INPS do salário-maternidade, bem como no período posterior até os dias atuais.

Para efeitos comparativos e de avaliação da nossa pergunta deduzida do emprego em escala maior da mulher casada após essa Lei, estabeleceremos semelhantes entrevistas em empresas metalúrgicas que passaram a utilizar mão-de-obra feminina após 1974. Os Sindicatos de classe também estarão sob a técnica do survey para levantarmos material empirico ligados ao fluxo demissão - readmissão, rotatividade de mão-de-obra e interpretações frente ao mecanismo da estabilidade, F.G.T.S. e do arrocho-salarial.

Junto à Justiça do Trabalho local iremos tentar detectar os efeitos espoliatórios advindos do FGTS, instituído em 1966. Estudaremos o período anterior à instituição desse mecanismo e a sua posterior aplicação neste Município após 1966.

\section{BIBLIOGRAFIA.}

BOSI (Ecléa), Cultura de Massas e Cultura Popular: Leituras Operárias. Petrópolis, Vozes, 1972.

BERLINCK (Manoel T.), Marginalidade Social e Relações de Classes em São Paulo. Petrópolis, Vozes, 1975.

CARVALHO (Maria Luiza de), A Mulher no Mercado de Trabalho Brasileiro. In: Revista "Vozes", Petrópolis, Vozes, ago. 1972, n 6, v. LXVI, p. 461 .

COSTA (Rubem Vaz da), "A Mulher no Brasil II". Folha de São Paulo, 29 jun. 1975, p. 2, 1 c. 
GILBERT (Madeleine) e ISAMBERT-JAMATI (Viviane), "A Distribuição por Sexo". In: FRIEDMANN (Georges) e NAVILLE (Pierre), org. Tratado de Sociologia do Trabalho. São Paulo, Cultrix, 1973, v. 1, p. 304-323.

HARNECKER (Marta), Os Conceitos Elementais do Materialismo Histórico. Santiago, s. ed., 1973.

MARTINS (Itaboraí), Trabalho de Mulher está cercado de preconceitos. " $\mathrm{O}$ Estado de São Paulo", 05 mar. 1972, p. 29.

PLANISUL. Projeto de Implantação do Distrito Industrial, v. II. Joinville. Prefeitura Municipal de Joinville, 1975.

REZENDE (Zéia Pinho), A Participação da Mulher na Força de Trabalho. "A Notícia", Joinville, 30 jan. 1976, p. 4.

SAFFIOTTI (Heleieth. I. B.), A Mulher na Sociedade de Classes: mito e realidade. São Paulo, Quatro Artes, 1969. 